\title{
A photovoltaic solar system applied to rural household in Peru
}

\author{
Juan José Milón Guzmán ${ }^{1, *}$, Sergio Leal Braga ${ }^{2}$, Vivianyeli Garlet Ramos Mendoza ${ }^{1}$ and Brian Gilmar Ponce Valdivia ${ }^{1}$ \\ ${ }^{1}$ Universidad Tecnológica del Perú, Peru \\ ${ }^{2}$ Pontifícia Universidade Católica do Rio de Janeiro, Brazil
}

\begin{abstract}
The present research study aims to improve the efficiency of photovoltaic systems applied to homes in isolated areas. This experimental study was carried using a prototype of a rural house, located at the Technological University of Peru - Arequipa, Peru. The photovoltaic solar system, connected to the prototype house, supplied its electric loads (TV, Blu-ray, radio, refrigerator, blender, heater, washing machine, fan, iron), which were programmed to be turned on and off using digital timers during a period of 3 months (March, April and May 2020). The measured parameters were the solar power, the consumed electrical power and the electrical power of what would be an auxiliary source of energy (electric generator, for example) in case the solar resource is unavailable. The results indicate that the photovoltaic solar system could store the unused solar energy to supply the nighttime electrical loads, ensuring, in this way, the autonomy of the energy system.
\end{abstract}

\section{Introduction}

Currently electricity-intensive companies are seeking to generate energy in a cleaner and less expensive way, in order to take into account the conservation and preservation of natural resources that may be in danger of extinction [1].

The use of fossil fuels generates costs that vary every day due to problems attaining oil production areas. Oil exploitation causes pollution, affects many ecosystems, and is a subject of constant debate since the conservation of the environment and the financial factors are hard to balance. The rise of the fuel price of and the costs of reducing the environmental impact are two determining aspects that need to be accounted for when planning energy production that satisfies the demand for electricity and guarantees social and economic development [2]

Photovoltaic systems are beneficial for isolated populations since they have a lower environmental impact on communities [3]. For this reason, this project proposes the improvement of the efficiency of an autonomous photovoltaic system applied to rural homes in isolated areas of Peru as an alternative for a better use of solar energy.

In recent years, solar energy has been one of the renewable sources with the highest demand in the world. There has been a remarkable growth in most of the world's markets, along with a higher use of solar panels compared to the use of other types of renewable energy devices, such as wind turbines. Currently there are two types of photovoltaic systems: (1) systems that are linked to the grid and (2) isolated systems that produce electricity autonomously and have batteries packs for storage and to ensure the regulation of the electricity delivered to meet the required demand. Different research studies have analyzed the operational performance of photovoltaic systems connected to the electrical network to supply energy to buildings [4] [5] [6] [7] [8], analyzing mainly the energy efficiency of the systems. There are as well research studies that highlight the electrochemical storage of photovoltaic solar energy using different technologies [9] and intelligent systems [10]. Regarding isolated systems, there are studies that have considered mathematical [11] [12] and experimental models [13] [14].

After the literature review, no relevant studies referring to the optimization of photovoltaic systems installed in rural and isolated areas were found. Thus, this paper will focus on an evaluation and the optimization of a photovoltaic system applied to rural homes in isolated areas of Peru.

\section{Experimental approach}

This chapter details the design and development of the research (Figure 1). The experimental model was made up of a photovoltaic module, an electrical load module and a monitoring and control module.

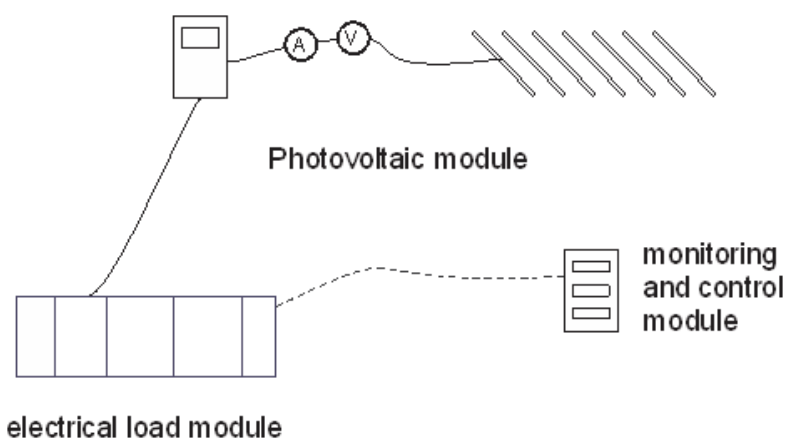

Fig. 1 General representation of the experimental model.

\footnotetext{
* Corresponding author: jmilon@utp.edu.pe
} 


\subsection{Photovoltaic system}

The photovoltaic system had three monocrystalline solar panels. Its characteristics are described in Table 1.

Table 1. PV panels technical specifications.

\begin{tabular}{|l|l|}
\hline Power per unit $(\mathrm{Pm})$ & $275 \mathrm{~W}$ \\
\hline Open circuit voltage $\left(\mathrm{V}_{\mathrm{oc}}\right)$ & $38.5 \mathrm{~V}$ \\
\hline Short circuit current $\left(\mathrm{I}_{\mathrm{sc}}\right)$ & $9.15 \mathrm{~A}$ \\
\hline Maximum power voltage $\left(\mathrm{V}_{\mathrm{mp}}\right)$ & $31.3 \mathrm{~V}$ \\
\hline Maximum power current $\left(\mathrm{I}_{\mathrm{mp}}\right)$ & $8.79 \mathrm{~A}$ \\
\hline Area & $0.648 \mathrm{~m}^{2}$ \\
\hline
\end{tabular}

An inverter, which specifications are detailed in Table 2, was used.

Table 2. Inverter's technical specifications.

\begin{tabular}{|l|c|}
\hline \multicolumn{2}{|l|}{ Technical specifications } \\
\hline Power (Pm) & $3000 \mathrm{~W}$ \\
\hline Admissible ambient & $-40{ }^{\circ} \mathrm{C}$ to \\
temperature & $55^{\circ} \mathrm{C}$ \\
\hline Maximum current input & $18 \mathrm{~A}$ \\
\hline Maximum efficiency & $96.9 \%$ \\
\hline Nominal frequency & $60 \mathrm{~Hz}$ \\
\hline
\end{tabular}

The system has a power control panel, which is located inside the prototype house, next to the inverter. This panel is responsible for managing the supply to the house from the solar system and/or the auxiliary source. It is made up of two thermo-magnetic switches and a smart meter.

The monitoring and control module is composed of electrical sensors (for the electrical power, photovoltaic power, and energy consumption of the electrical load). All signals were registered and processed in a spreadsheet.

\subsection{Electric loads}

The list of home appliances used for the project is shown in Table 3.

Table 3. Electric loads.

\begin{tabular}{|c|c|c|}
\hline Quantity & Appliance & Power [W] \\
\hline 1 & Tv & 56 \\
\hline 1 & Fan & 50 \\
\hline 1 & Blender & 450 \\
\hline 1 & Blu Ray & 12 \\
\hline 1 & Radio & 100 \\
\hline 1 & Refrigerator & 180 \\
\hline 1 & Iron & 1200 \\
\hline 1 & $\begin{array}{c}\text { Washing } \\
\text { machine }\end{array}$ & 1000 \\
\hline 1 & Electric heater & 600 \\
\hline
\end{tabular}

\section{Experimental procedure}

The appliances used for the project were programmed individually to determine the turn-on and turn-off time, using typical values for a rural house in Peru (http://www.inei.gob.pe/). The evaluation period took. Place between October 2019 and September 2020.

\subsection{Analysis and data reduction}

\section{Energy consumption}

It is the energy consumed by an appliance. The unit of measurement of energy consumption is $\mathrm{W} \mathrm{h}$.

$$
\mathbf{T C}=\mathrm{SC}+\mathrm{EAS}
$$

Where:

$\mathrm{TC}=$ Total consumption $[\mathrm{W} \mathrm{h}]$

$\mathrm{SC}=$ Self consumption [W $\mathrm{h}$ ]

EAS $=$ Energy from auxiliary source $[\mathrm{W} \mathrm{h}]$

\section{Production}

The electricity production occurs through the transformation of another kind of energy, in this case, solar energy.

$$
\mathbf{P F}=\mathrm{SC}+\mathrm{SP}
$$

Where:

$\mathrm{PF}=$ Photovoltaic production $(\mathrm{W} \mathrm{h})$

$\mathrm{SC}=$ Self consumption $(\mathrm{W} \mathrm{h})$

$\mathrm{SP}=$ Surplus $\mathrm{PV}$ production $(\mathrm{W} \mathrm{h})$

\section{Uncertainty Analysis}

The uncertainties associated to the measurement process are shown in Table 4 [15]

Table 4. Measurement uncertainties.

\begin{tabular}{|l|c|c|}
\hline Parameters & $\begin{array}{c}\text { Uncertainties, } \\
\%\end{array}$ & Reference \\
\hline Irradiance & 0.5 & {$\left[\left(\frac{\delta \mathrm{t}}{\mathrm{t}}\right)^{2}+\left(\frac{\delta \mathrm{I}_{\mathrm{s}}}{\mathrm{I}_{\mathrm{s}}}\right)^{2}\right]^{0.5}$} \\
\hline $\begin{array}{l}\text { Electric } \\
\text { current }\end{array}$ & 0.5 & Instrument \\
\hline Voltage & 0.1 & {$\left[\left(\frac{\delta \mathrm{I}}{\mathrm{I}}\right)^{2}+\left(\frac{\delta \mathrm{V}}{V}\right)^{2}\right]^{0.5}$} \\
\hline $\begin{array}{l}\text { Electric } \\
\text { power }\end{array}$ & 0.5 & \\
\hline
\end{tabular}

\section{Results and analysis}

Figure 2 shows the solar energy production corresponding to a typical weekend (Saturday and Sunday) in March 2020. It can be observed that photovoltaic electricity was produced from approximately $6: 30 \mathrm{~h}$ to $17 \mathrm{~h}$. From $6: 30 \mathrm{~h}$. to $10: 00 \mathrm{~h}$, the electricity demand was entirely supplied by the solar system, leaving a surplus of unused energy. From $10 \mathrm{~h}$ to $12 \mathrm{~h}$ five electric loads were activated (washing machine, refrigerator, fan, radio and blender), this is why the total consumption exceeded the production capacity. In order to supply this additional demand, another energy source (generator) was needed. As well, from noon to $17 \mathrm{~h}$ the 
production of photovoltaic energy decreased and, since the system did not include an energy storage device, the consumption had to be supplied by another source of energy.

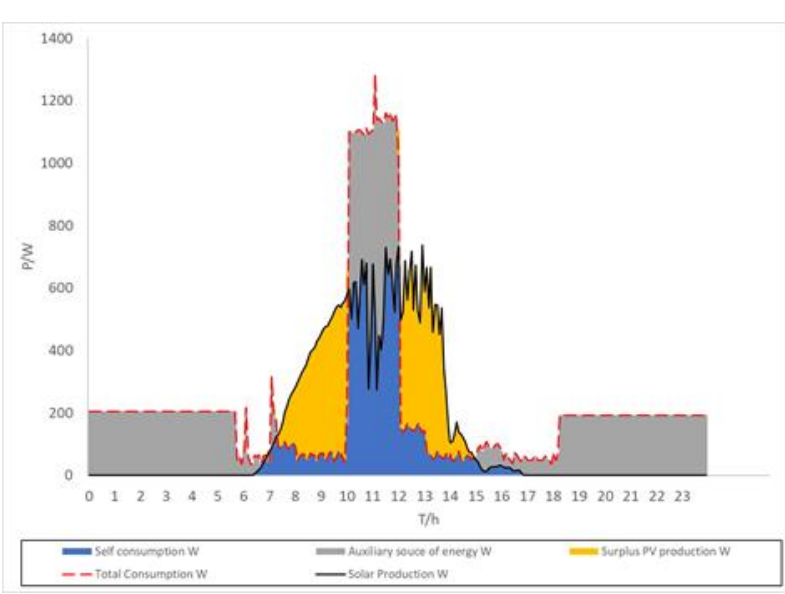

Fig. 2. Energy consumption during a weekend, March 2020.

Figure 3 shows the solar energy production corresponding to a typical weekday (Monday to Friday) in March 2020. It is observed that the production of photovoltaic energy occurred from $6: 30 \mathrm{~h}$. to $15: 30 \mathrm{~h}$, with the highest production peak $(600 \mathrm{~W})$ at approximately $12: 30 \mathrm{~h}$. During those hours, it was possible to supply the prototype house's electric loads. From 3:30 pm photovoltaic energy was no longer produced, which is why consumption had to be supplied by another type of energy supply source (generator).

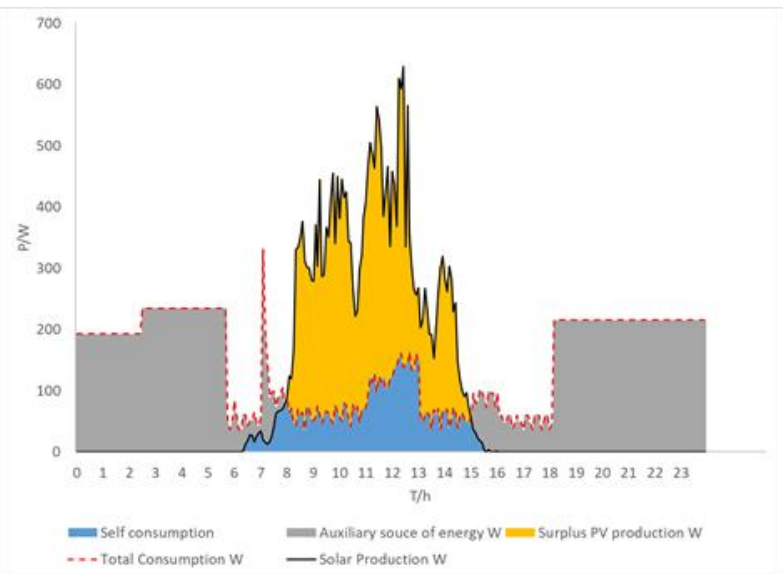

Fig. 3. Energy consumption on weekdays, March 2020.

Figure 4 shows the energy production corresponding to March 2020. It can be observed that on days 3 and 4 there was a higher production of solar energy: during these days with higher solar radiation the photovoltaic energy production attained between $4500 \mathrm{~W}$ h to $4600 \mathrm{~W}$ $\mathrm{h}$, unlike day 17 , which was less sunny, resulting in a production of approximately $1000 \mathrm{~W}$ h. During March 2020, 93,503 W h were produced.

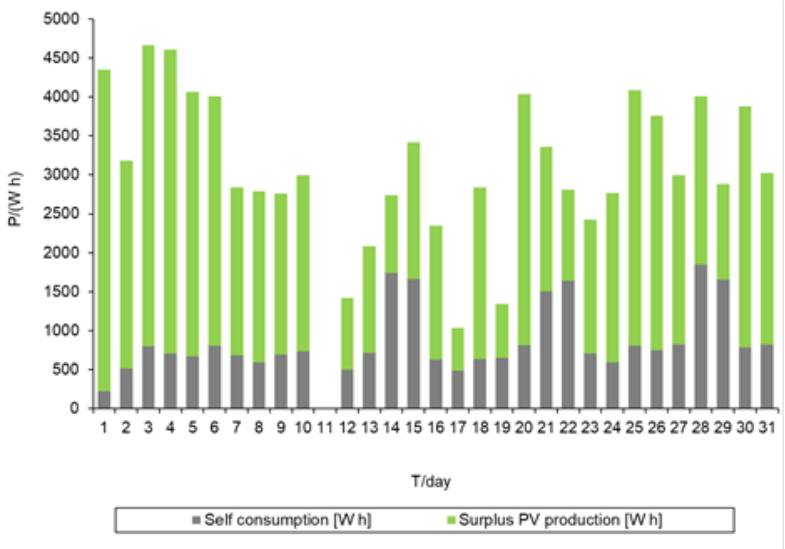

Fig. 4. Variation of energy production in March 2020.

Figure 5 shows the energy costs corresponding to March 2020 based on the current cost of electricity in Arequipa, Peru. It can be stated that the total production of photovoltaic energy amounted to 5.3 USD. Direct consumption can be valued at 1.5 USD, considered as savings, which leaves a total of 3.8 USD as unused solar PV energy. Since the total consumed energy amounted to 5.3 USD, the supplementary energy provided to the system was equivalent to 3.8 USD.

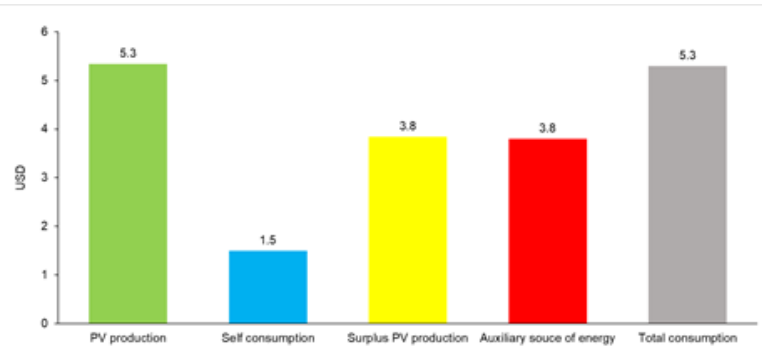

Fig. 5. Cost analysis of energy production in March 2020.

Figure 6 shows the cost analysis corresponding to the entire year (from October 2019 to September 2020). The total production of photovoltaic energy amounted to 69 USD, the lost unused photovoltaic energy was of 50 USD, the savings were equivalent to $20 \mathrm{USD}$, and the cost of using a complementary energy source was of 50 USD, with a total consumption equivalent to 71 USD.

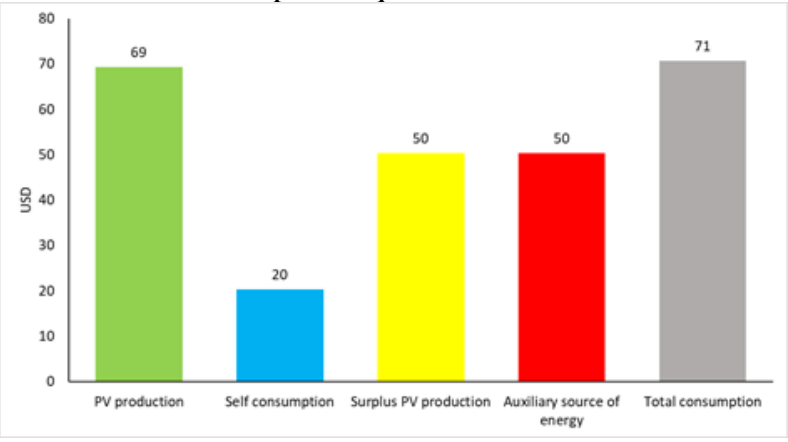

Fig. 6. Yearly cost analysis. 


\subsection{Electrochemical storage}

Transporting fuel and spare parts for internal combustion engine generators to rural and isolated regions of Peru is complicated and expensive. In order to be autonomous, photovoltaic systems require a complementary source of energy, be it another renewable energy source (wind, hydraulic, mainly) or non-renewable (internal combustion generator) that complements them during periods with low solar radiation or at night. Another strategy to guarantee a continuous and high-quality electricity supply is energy storage (batteries, dynamic wheels, capacitor banks, etc.).

For the present research study, battery-based storage was tested, since it is generally a more attractive option due to the ease of adaptation to photovoltaic installations. By storing electrical energy in the form of chemical energy, batteries represent the most appropriate technology to complement the energy supply in conjunction with photovoltaic systems. Figure 6 shows that the unused solar energy is very similar to the energy supplied by the complementary energy source. This fact was important to determine that the unused solar energy could be stored in batteries, since the proposed battery technology should be able to guarantee the operation of the entire photovoltaic system. In many cases, the use of inappropriate batteries caused the photovoltaic system to stop working in a few months, reducing the trust people have on the technology. Currently, lithium-ion batteries are the most appropriate, but they are available at higher costs.

\subsection{General perception of rural populations on electricity consumption}

In rural areas, there are some electrical loads operating at night that could be partially shifted to daytime hours. However, this would not always be possible due to the population habits and routines rooted on their culture for centuries. More importantly, the characteristics of their activities include a working rhythm that imposes them to be away from home almost all day.

Based on the data generated regarding the production of photovoltaic energy and considering the consumption schedule of the loads, it is observed that photovoltaic energy is produced only from $6 \mathrm{~h}$. to $17: 30 \mathrm{~h}$ and that from 17:30 h to $6 \mathrm{~h}$, three loads (TV, refrigerator and heater) start to operate. The refrigerator is a constant load because it works 24 hours and the TV's load depends on people's different habits, but it is generally used at night. However, the heater's load could be shifted to daytime hours, by using passive radiators or hot surfaces (solar thermal). In this way, heating could be provided to the house using another type of source, thus reducing the consumption of photovoltaic energy. This alternative depends strongly on the habits of the house inhabitants. This constitutes a challenge for photovoltaic projects, because technology can be very useful, but the optimum use of the resource will depend on the behavior and adaptation of people to the inclusion of renewable energies in their daily activities.

\section{Conclusions}

Photovoltaic solar energy is an important alternative for isolated rural regions of Peru, since it is reliable and constant throughout the day. This energy source represents savings that could translate into an improvement in people's quality of life. It is estimated that the implementation of battery storage for a photovoltaic system induces a complementary investment of $20 \%$. Considering the technical aspect, energy storage using electric batteries considerably improves the performance of the photovoltaic system, allowing a better quality of energy during the night hours and guaranteeing the energy supply during hours with low solar radiation. Furthermore, concerning environmental aspects, solar photovoltaic systems' benefits place it far ahead of fossil fuels-based energy generating alternatives.

It is important to highlight how the adequacy of these systems to energy consumption needs and their efficiency depend on the users, their habits and their daily activities.

\section{References}

1. P. Humberto, R. López and R. Luna, Diseño de un Sistema Fotovoltaico integrado a la red para el área de estacionamiento de la Universidad Tecnológica de Salamanca, Chihuahua, Mexico, 2014.

2. G. A. Carlos Manuel, C. Ivan Massipe, R. R. Raciel, R. G. María and V. P. Antonio, "Factibilidad de instalación de sistemas fotovoltaicos conectaos a red," Ingeniería Energética, vol. Vol. XXXV, Cuba 2013.

3. P. V. Aixa, Evaluación técnico-económica de una instalación de bombeo solar fotovoltaica aplicada a la ampliación de la frontera agrícola en zonas aisladas de Arequipa, Arequipa Perú, Noviembre 2018.

4. F. Cherfa, A. Hadj Arab, R. Oussaid, K. Abdeladim and S. Bouchakour, "Performance Analysis of the Mini-grid Connected Photovoltaic System at Algiers," in 7th International Conference on Sustainability in Energy and Buildings, Algiers, 2015.

5. B. Ilham, Y. Ali, A. Kamal, L. Zouhir and A. Adel, "Performance investigation of a PV system connected to the grid," Procedia Manufacturing, p. 8, 2018.

6. V. Salas and E. Olias, "Overview of the state of technique for PV inverters used in low voltage grid-connected PV systems: Inverters below $10 \hat{A}$ kW," Renewable and Sustainable Energy Reviews, p. 8, 2009.

7. V. Luis, C. Manuel and B. Arturo, "Grid Connected Photovoltaic Systems to the Urban 
Environment of Argentinian Northeast," Energy Procedia , 2014.

8. A. Aganza, V. Cárdenas, M. Pacas and M. Gonzales, "An efficiency comparative analysis of isolated multi-source grid-connected PV generation systems based on a HF-link microinverter approach," Solar Energy, p. 9, 2016.

9. J. Marcin, W. Szymon and W. Bartosz, "Comparative analysis of selected energy storage technologies for prosumer-owned microgrids," Renewable and Sustainable Energy Reviews, 2017.

10. E. Velasco, A. Camacho and M. García, "Smart Transmission Grids - Benefits and Risks," Ingenería, Investigación y Tecnología, vol. XIV, no. 1, pp. 81- 88, 2013.

11. S. Leticia, R. Carlos and R. Giuliano, "A relative power-based adaptive hybrid model for DC/AC average inverter efficiency of photovoltaics systems," Renewable and Sustainable Energy Reviews, p. 8, 2018.

12. O. D. Thierry Odou, R. Bhandari and R. Adamou, "Hybrid off-grid renewable power system for sustainable rural electrification in Benin," Renewable Energy, pp. 1266-1279, 2018.

13. R. Opoku, K. Mensah and A. Samed, "Technoeconomic analysis of a hybrid solar PV-grid powered air-conditioner for daytime office use in hot humid climates - A case study in Kumasi city, Ghana," Solar Energy, pp. 65-74, 2018.

14. B. Carlos, G. T. Feliz and V. Luis, "Gestión óptima de la energía en microrredes con generación renovable," Revista Iberoamericana de Automática e Informática industrial, 2015.

15. M. Robert, Describing the Uncertainties in Experimental Results, Stanford University, Stanford, California, 1988. 